\title{
Students' Perception of Learning in the Online Discussion Environment
}

Tatiana Krasnova

\author{
Lecturer, National Research Tomsk Polytechnic University; E-mail: krasnova@tpu.ru
}

\section{Alexandr Ananjev}

Undergraduate student, National Research Tomsk Polytechnic University; E-mail: holypatrickcow@gmail.com

\author{
Doi:10.5901/mjss.2015.v6n6s1p202
}

\begin{abstract}
Online courses have become a part of academic initiatives to supplement instruction in a blended learning format. They create numerous opportunities for collaborative learning based on learner-centred approach. Asynchronous online discussion forums set an environment developing a sense of community and engaging students in collaborative discussions making them meaningful learning activities. The main benefit of such activities for students is generating new knowledge and sharing it with peers. Online discussions open up new vistas on students' writing skills and make them exposed to a range of alternative viewpoints. This paper reports about the investigation of asynchronous online discussion efficacy in the learning process. Students' attitudes and expectations in such type of online collaboration were analyzed in order to present student's perception of learning in the online discussion environment. The findings of this study indicate certain benefits and positive overall perception though some problems were identified and potential solutions were highlighted.
\end{abstract}

Keywords: asynchronous online discussion, Moodle, online course.

\section{Introduction}

Technological advancements, growth of Internet importance in everyday life and usage of mobile communication technologies affected education as well. International academic community recognizes the fact that the transfer to information society is impossible without integration of e-learning technologies into the educational process. These technologies orient learners to a contemporary educational mode promoting their knowledge and skills development for lifelong learning and personal development during a lifetime.

Higher education in Russia is affected by significant changes and these changes are inevitable if we want to respond the demands of the society. The flexibility of education with a student-centered approach has become a leading idea now. Modern education should take into account individual peculiarities of students, their diverse personal work styles, studying habits, and individual pace, thus it should provide the students with self-paced learning. This need for flexibility brings to life a blend of traditional face-to-face instruction and online delivery using different Learning Management Systems (LMS). This method exposes academics to new ideas and practices and makes the educational process learner-centered and result-focused.

Blended learning can be defined as a method of teaching that combines the most effective face-to-face teaching techniques and online interactive collaboration, both constituting a system that functions in constant correlation and forms a single whole (Krasnova, 2015). The main challenge is to find the right balance between the traditional mode of delivery and the online one.

Some of the commonly recognised advantages of blended learning include flexibility, personalisation and interactivity derived from an online component and direct observation, immediate feedback and spontaneity inherent from conventional teaching (Rybushkina \& Krasnova, 2015). A blend of online and face-to-face activities is widely recognised and quite common today in European and American institutions.

In Russian higher education sphere blended learning is a relatively new phenomenon but a lot of universities try to adopt best practices and to integrate this method in the educational process. The aim of these initiatives is to facilitate learning, teaching and research by providing information and communication technologies (ICT) tools and making it easy to access digital learning resources (European Commission, 2014).

Blended learning offers new exciting opportunities for foreign language teaching as it allows intensifying traditional teaching forms and methods and thereby influencing positively the process of foreign language acquisition in whole 
(Krasnova, 2015). The importance of raising foreign language teaching efficacy has increased dramatically. Foreign language proficiency is highly demanded for fulfilling challenging goals and can have a positive impact on transforming engineering education in Russia. Professional competence of any specialist is strongly connected with the ability to communicate in other languages. Technological innovations facilitate better quality learning and help overhaul the content and approaches to teaching foreign languages to nonlinguistic students (Sidorenko, Igna, Rybushkina \& Didenko, 2013).

Nowadays, the main challenge facing the teacher of foreign languages is to develop and implement methods of organized and systematic use of information and communication technologies for educational purposes (Buran, 2015). Due to limited number of contact hours for foreign language courses in engineering universities Tomsk Polytechnic University (TPU) intensifies the learning process by active integration of ICT. The university puts particular emphasis on e-learning technologies where blended learning method takes a special place. Since 2014 the majority of foreign language courses at TPU became blended with the help of Moodle platform, which is considered an official university Learning Management System.

The objective of the study presented in this paper was to describe students' experiences and perception of online discussions based on a questionnaire and interviews. Students' interaction in discussion forums was explored in order to identify the advantages of this type of online activity. Students' views on problems occurring during online discussions such as low level of participation and reasons for non-posting were analyzed as well.

\section{Online Collaboration}

Developing interpersonal skills through online collaboration is an integral part of preparation for future career. Tertiary education should develop students' understanding of teamwork, critical thinking and adaptability by introducing groupbased activities that encourage meaningful collaboration and have real-world application. Collaboration is the main feature of future work environment and should be reflected in authentic activities thoroughly designed by educators. Such activities promote fast solving of difficult cognitive tasks and better understanding and adoption of new material.

The main features of collaboration are purposefulness, aspiration for the common goal, motivation, interest, integrity, participants' interconnection, efficient distribution of roles, functions and duties, conformity, low conflict level, self-discipline, ability to achieve the result. But as it was mentioned earlier collaboration is not an end in itself; it is used to help students acquire knowledge and skills, communication experience and social activity. When students recognize themselves as part of a team and understand that common success depends on their individual efforts and contribution, their attitude and position change they have to show initiative and self-sufficiency.

Not long ago collaboration was possible only in the classroom but now Moodle creates collaborative learning environment where online discussion forums become a main form of asynchronous communication.

\section{Asynchronous Online Discussion Forum}

Asynchronous online discussion forum is an invaluable tool for learning foreign languages as it facilitates students' communication beyond the classroom and allows participants to interact with each other without any time and place restrictions. A lot of studies find prominent benefits of online discussions.

Mbati (2013) considers online discussions a powerful motivating tool both for students and lecturers. Students need a new fresh approach which will make their learning process more appealing. In this respect online discussions offer new exciting opportunities being a very motivating resource.

Lapadat (2002) thinks that asynchronous online discussions promote better critical thinking as they are written and even further enhance the higher order thinking processes. Cook (2008) also claims that online discussions can develop skills involved in critical thinking. They can help students consider alternative viewpoints, develop new insights, draw supported conclusions and build arguments by providing textual or anecdotal evidence.

One unique feature of asynchronous online discussion forum is that there is no loss of data as the discussion forum allows records of an individual's written messages to be kept in the virtual space (Hew, Cheung \& $\mathrm{Ng}, 2010$ ). Participants can respond the posted messages at any time they wish and to any student they choose.

Online discussion promotes student-to-student interaction while classroom discussion consists mostly of utterances which are responses to the teacher who takes traditionally a moderator role.

Delayed answer is one more benefit of online discussions, students don't need to give immediate response as it is common during classroom discussions; they can view the post and respond in asynchronous manner. Students have time to think and reflect on their answers and other students' comments. In this case they construct their ideas more carefully and analyze the whole situation more thoroughly, therefore their utterances become longer. 
Students who do not usually contribute in traditional classroom discussions for certain reasons have an opportunity to express their ideas freely without being dominated by strong students. Their participation in online discussions increases the number of alternative viewpoints in comparison with the traditional classroom discussion.

However, there is much disappointment among instructors when they see that some discussions fail and bring to a deadlock. Students seem to only respond in order to complete the assignment thus making the discussion pointless.

There are usually three widespread problems of online discussions:

- limited student contribution;

- surface-level posts;

- low-level grammar constructions and improper vocabulary use.

Limited student contribution can be defined as absence or limited number of posts. Usually this problem is connected with procrastination and can't be easily solved but certain time limits for the task usually improve the situation. Another problem is surface-level posts containing useless information without expressing any opinion on the discussion problem. Some students write messages just for the sake of participation, they repeat or paraphrase other students' ideas and don't contribute anything new or valuable to the discussion. The moderator of the discussion or teacher should stop these practices and encourage such students to a more productive mode. Low-level grammar constructions and improper vocabulary use can disturb other participants' understanding. These students can be advised to use reference materials, dictionaries, in addition the participants may ask additional questions in order to understand what they mean.

\section{Methods and Data Analysis}

On the basis of "General English Blended Course" for first year students of TPU, which provides online materials as supplementary resources to the main course, we will try to explore such element as asynchronous online discussion forum. The semester course consists of 6 modules, each of which has a section called "Team work" with online discussions and wikis. Discussion forums are set for small group of students (8-10 participants), who should give their opinions on the issue given by the teacher. Then they should read the opinions of other participants and comment on at least 2 of them. If there are no posts to comment, they should return later. Forums have peer assessment instrument, students can assess the posts of their group-mates from 0 to 5 according to the rubric given in the Forum Instruction. The discussion issue is usually based on course-related topics. Example issues for Module 3 "Healthy Lifestyle" were the following:

- GM food: helpful or harmful?

- Diets are the key to weight loss. Do you agree?

- Fast food restaurants should be blamed for obesity. Do you agree?

- Employees should always be fired for failing the drugs test. Do you agree?

In Figure 1 there is an example of online discussion:

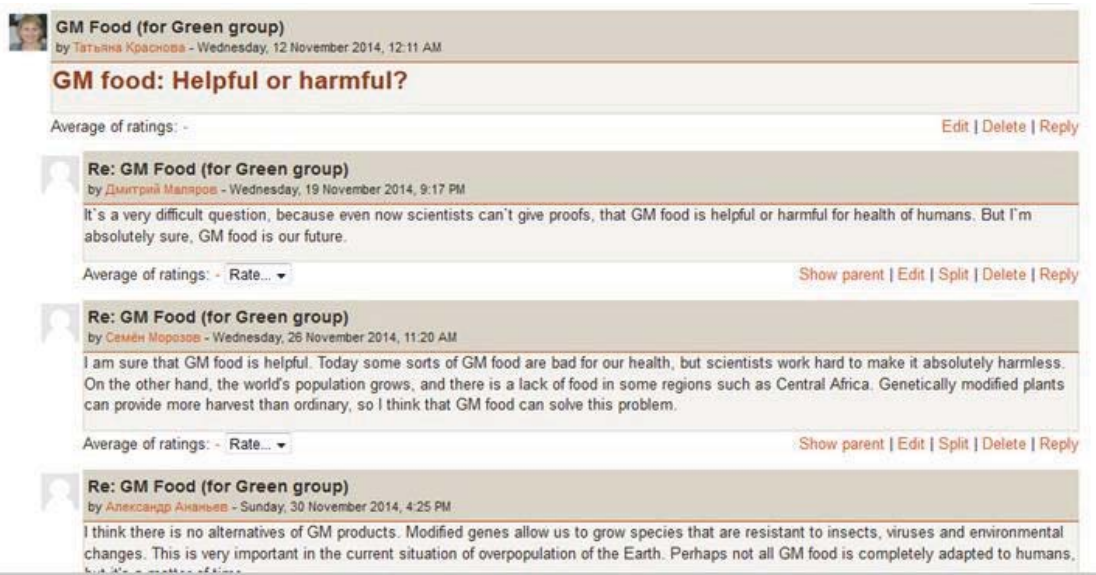

Figure 1. Online Discussion in General English Blended Course 
The criteria for discussion assessment are presented to students in advance and include the following:

- the content should be complete and accurate, offer new ideas;

- the ideas should be supported with details that explain student's opinion;

- the content of the message should encourage further discussion on the issue;

- the message is characterized by relevance and originality;

- the participant completed the task within the required timeframe;

- the participants commented on at least 2 other students;

- the participants raised other relevant questions.

Quantitative methods were employed to collect the data that contribute to the understanding of the phenomena studied. With the purpose of finding out students' attitudes to online discussions a survey research was conducted.

The main questions underlying the study were:

1. What is the overall perception of asynchronous online discussions by students?

2. What are students' expectations from asynchronous online discussions?

The study was carried out among 46 enrolled undergraduate students (11 female and 35 male) getting a Bachelor degree at TPU in the spring term of 2014-2015 academic year. The students participated regularly in asynchronous online discussions during the academic year.

Table 1 shows online discussion participation details:

Table 1. Asynchronous online discussion details

\begin{tabular}{|l|c|}
\hline Number of participants & 46 \\
\hline Number of online discussions & 5 \\
\hline Number of threads & 10 \\
\hline Number of postings & 326 \\
\hline
\end{tabular}

The survey contained 9 questions with empty boxes for writing the answers and 1 question with checkbox items.

\section{Results}

Most students $(89,2 \%)$ found asynchronous online discussions beneficial to their language learning and called them the key component of the online course. They encourage students to express ideas, share experiences, improve writing skills, and practice grammar and vocabulary. While some students (10.8\%) think that traditional discussions are better, and online discussions are completely useless and just a waste of time.

On average students contribute 2 messages: one of which is their opinion and the other is a comment of somebody's post. Therefore a discussion thread of a typical language group of 10 students contains not more than 20 postings, sometimes even less, because some students didn't contribute at all.

In comparison with traditional classroom discussions students pointed out the following advantages of online discussions:

- opportunity to choose convenient time for a discussion;

- enough time to think over the topic;

- development of writing skills;

- lack of interruptions and ability to express full thoughts;

- non-linear format of discussion which allows to respond to any participant;

- opportunity to consult a dictionary.

The majority of students $(95,6 \%)$ believe that online discussions promote thoughtful, in-depth reflection on discussion issues. Unlike the spontaneous classroom discussions through the asynchronous communications they were able to take the time to reflect and prepare a response for discussion topics (Yamagata-Lynch, 2014). But the other group of students $(4,4 \%)$ thinks that they acted the same as in the traditional discussion in the classroom.

91, 3\% of students confessed that they experience procrastination problem while participating in online discussions. Students put off this task up to the deadline that is why the discussion can move forward very slowly at the beginning and become very active at the end. The main reasons were called; these were laziness and lack of selfdiscipline.

Students usually have 1 week for a discussion and 95,6\% believe that allocated time is enough to participate in it 
and only $4,4 \%$ want it to be longer.

Some students prefer to be lurkers through their interaction and experiences with the community; they rarely participate in discussions (Küçük, 2010). Table 2 shows the reasons why students don't participate in asynchronous online discussions.

Table 2. Reasons for non-posting

\begin{tabular}{|l|c|c|}
\hline Reasons & Number of participants & Percentage \\
\hline Nothing to offer & 23 & $50 \%$ \\
\hline Others responded the way I would & 33 & $71,7 \%$ \\
\hline There are too many posts already & 0 & $0 \%$ \\
\hline Not enough time to read and post & 17 & $36,9 \%$ \\
\hline Long delay in response to posting & 16 & $34,7 \%$ \\
\hline Shy about posting & 3 & $6,5 \%$ \\
\hline Poor quality of previous messages & 6 & $12,8 \%$ \\
\hline Just reading is enough & 0 & $0 \%$ \\
\hline
\end{tabular}

As we see from Table 2 the most common reasons for non-posting in online discussions are that others have already responded the way the student wanted and lack of ideas. Long delays and strict time limit can also cause problems and prevent them from participating. Some students consider the posts of their group-mates of low quality and therefore lose motivation to continue the discussion. There are 3 shy students who are still afraid of posting their ideas and no one thinks that 'just reading' is enough for participation in online discussions. 'Too many posts' wasn't chosen as a reason for not participating probably because they understand that individual performance is assessed.

As for overall attitude to online discussions we can figure out that it positive. They admit that it is a way of communication and good for practicing English. Some students mentioned that they don't like discussions at all and it doesn't matter if they are online or traditional ones. They don't expect anything special from this type of activity as it is quite common but want to have more interesting and relevant issues for discussion. Some students told that other groups' topics were more fascinating and challenging than theirs.

\section{Conclusion}

Transition to a new educational paradigm using e-learning technologies enables new unique opportunities for students. New innovative technologies and traditional pedagogical approaches are blended giving access to a wider range of materials. Online courses on Moodle platform offer engaging and highly motivating activities that positively affect students' performance and promote their progress. Asynchronous online discussions are primary component of online language courses, they give the opportunity to interact, reflect and collaborate. The study proves that online discussion is students' favourite activity; they feel comfortable in online environment and express their ideas more freely and in a more descriptive way. Online discussion environment being the integral part of all blended courses gives the students the opportunity to be active and achieve outstanding results in foreign language acquisition.

\section{References}

Buran, A. L. (2015). How to Use Blogs in Creating Special Opportunities for Language Learning. Mediterranean Journal of Social Sciences, 6 (1). 532-536.

Cook, N. A. (2008). Online discussion forums: A strategy for developing critical thinking in middle school students. ProQuest.

European Commission/EACEA/Eurydice, (2014). Modernisation of Higher Education in Europe: Access, Retention and Employability 2014. Eurydice Report. Luxembourg: Publications Office of the European Union. Retrieved from http://files.eurashe.eu/library/ eurashe_ac_yerevan_15-160514_pres_riihelainen_paper-pdf/

Hew, K. F., Cheung, W. S., \& Ng, C. S. L. (2010). Student contribution in asynchronous online discussion: A review of the research and empirical exploration. Instructional Science, 38(6), 571-606.

Krasnova, T. (2015). A Paradigm Shift: Blended Learning Integration in Russian Higher Education. Procedia-Social and Behavioral Sciences, 166, 399-403.

Küçük, M. (2010). Lurking in online asynchronous discussion. Procedia-Social and Behavioral Sciences, 2(2), 2260-2263.

Lapadat, J. C. (2002). Written interaction: A key component in online learning. Journal of Computer-Mediated Communication, 7(4), 0-0.

Mbati, L. (2013). Discussion Forums and Weblogs: A Means to Fostering Learning. Mediterranean Journal of Social Sciences, 4(13), 513-518. 
Rybushkina, S., Krasnova, T. (2015). Key Factors to Use Blended Learning in Teaching Foreign Languages in Russian Engineering Universities. EDULEARN15 Proceedings, 6886-6892.

Sidorenko, T.V., Igna, O.N., Rybushkina, S.V., Didenko, A.V. (2013). On the Issue of Foreign Language Training in non Linguistic Universities Abroad. In the World of Scientific Discoveries, Series A, 1 (1), 87-100.

Yamagata-Lynch, L. (2014). Blending online asynchronous and synchronous learning. The International Review of Research in Open and Distributed Learning, 15(2), 189-212. Retrieved from http://www.irrodl.org/index.php/irrodl/article/view/1778/2889. 